Revista Destaques Acadêmicos, Lajeado, v. 12, n. 1, 2020. ISSN 2176-3070

DOI: http://dx.doi.org/10.22410/issn.2176-3070.v12i1a2020.2474

http://www.univates.br/revistas

\title{
GESTÃO DE MICRO E PEQUENAS EMPRESAS: UM ESTUDO NO VALE DO TAQUARI/RS
}

\author{
Carlos Alberto Zanotelli ${ }^{1}$, Bernardete Bregolin Cerutti ${ }^{2}$
}

Resumo: Estudos científicos apontam um crescimento na criação de micro e pequenas empresas nas últimas três décadas no Brasil, devido, principalmente, a redução de empregos formais e a crescente competitividade decorrente das mudanças econômicas e tecnológicas. Tais mudanças refletem em iniciativas empreendedoras como estratégia para atender novas demandas de bens e serviços. Além disso, essas iniciativas empreendedoras contribuem para a movimentação da economia das regiões onde estão inseridas, pois mesmo sendo empresas de pequeno porte somam a maior parte dos rendimentos dos municípios brasileiros. Diante disso, este estudo tem o objetivo geral de analisar, a partir de gestores de micro e pequenas empresas, quais características consolidam seus negócios no mercado. Para atender ao objetivo geral, foram definidos os objetivos específicos, que são: (i) averiguar as características que constituem os gestores que consolidam negócios; e (ii) detectar facilidades e dificuldades para gerir micro e pequenas empresas. A base teórica que sustenta o estudo está apoiada em temas afins a gestão de micro e pequenas empresas. Mediante pesquisa qualitativa e estudo de casos múltiplos, realizou-se entrevistas semiestruturadas com cinco gestores de micro e pequenas empresas, de cinco diferentes cidades e diferentes ramos de atuação do Vale do Taquari/RS. Os dados da pesquisa são analisados com base nas aproximações teóricas da análise de conteúdo proposta por Bardin (2011). Os resultados demonstram que os participantes da pesquisa são empreendedores já estabelecidos no mercado, e iniciaram suas atividades pelo sonho de empreender. As características predominantes entre os respondentes e que consolidam seus negócios no mercado até o momento são: paciência, humildade, dedicação, foco, coragem e comprometimento. Contudo, estas características não são substitutivas à gestão de pessoas e de processos, quesitos estes que apareceram deficitários no estudo, pois dos cinco respondentes somente dois referiram utilizar gestão de processos.

Palavras-chave: Gestão. Micro e pequenas empresas. Características. Vale do Taquari/ RS.

1 Graduando do curso de Administração de Empresas da Universidade do Vale do Taquari Univates, Lajeado/RS. carlos.zanotelli@universo.univates.br.

2 Mestra em Ambiente e Desenvolvimento. Professora da Universidade do Vale do Taquari Univates, Lajeado/RS. bcerutti@univates.br. 


\section{INTRODUÇÃO}

Estudos científicos apontam um crescimento significativo de novos negócios nas últimas três décadas, devido, principalmente, à queda da taxa empregatícia formal, que gera necessidades e oportunidades para empreender (SCHMIDT; BOHNENBERGER, 2009). Dornelas (2012) destaca que frente ao desemprego gerado pelas variáveis econômicas, tecnológicas, sociais e culturais, muitos profissionais passam a investir em pequenos negócios.

Conforme o estudo da Global Entrepreneurship Monitor (GEM), a taxa de empreendedores em estágio inicial no Brasil em 2018 correspondia a $6^{a}$ posição no grupo dos 11 países classificados com "média renda" e a $10^{a}$ posição geral entre os 49 países pesquisados (GEM, 2018). E a taxa de empreendedores estabelecidos com mais de 42 meses de operação ocupava a $2^{a}$ colocação entre os 11 países classificados com "média renda" e a $3^{\text {a }}$ posição geral dos 49 países integrantes do estudo (GEM, 2018).

Nesta perspectiva, Bonacim, Cunha e Corrêa (2009) afirmam que gestores de micro e pequenas empresas são responsáveis pela movimentação econômica das regiões onde atuam, pois, mesmo sendo de pequeno porte somam a maior parte dos rendimentos dos municípios. Do ponto de vista de características e competências desses gestores, os mesmos autores acreditam que são virtudes pessoais ou adquiridas com o passar dos anos conforme o espaço e o ambiente que ocupam, assim como a cultura da sociedade.

Para Dolabela (2003), às empresas de micro e pequeno porte possuem papel fundamental para geração de novos empregos e tecnologias. Além disso, elas possuem uma cultura mais flexível e de adaptação às mudanças, conseguindo alinhar-se às diferentes situações presentes no mercado. Frente a essas colocações, o problema desta pesquisa consiste em identificar como as características e competências de gestores de micro e pequenas empresas do Vale do Taquari/RS contribuem para a consolidação de seus negócios no mercado?

Por isso, por meio de uma pesquisa qualitativa e de estudos de casos múltiplos, este artigo tem como objetivo geral analisar, a partir de gestores de micro e pequenas empresas, quais características e competências consolidam seus negócios no mercado. E, objetivos específicos de: (i) averiguar as características que constituem os gestores que consolidam negócios e (ii) detectar facilidades e dificuldades para gerir micro e pequenas empresas.

O interesse pelo estudo surge da experiência pessoal do acadêmico em formação. Por muitos anos vivenciando as atividades laborais da empresa familiar, tendo como proprietários os pais, enfrentou com estes inúmeras dificuldades para gerir a empresa, razão da escolha pelo curso de Administração, visando conhecer e compreender ferramentas que pudessem auxiliar na gestão.

A busca pela formação acadêmica continua, contudo, a participação na empresa familiar não mais, visto que não foi possível conviver com a resistência 
a novas práticas de organização e controle administrativo-financeiro, optandose pela permanência do bom convívio familiar em detrimento ao profissional.

Diante da experiência vivida, acredita-se que este trabalho contribuirá para um melhor entendimento sobre o perfil dos gestores e a forma de gerir as empresas, além de servir de subsídio aos profissionais que são ou desejam ter seu próprio negócio.

Assim, o artigo está organizado em seções. A introdução situou o leitor sobre o tema; a revisão da literatura busca embasar a realização do estudo; o método de pesquisa utilizado; e os resultados da pesquisa. Após, seguem as referências consultadas.

\section{REVISÃO DA LITERATURA}

Essa seção tem a finalidade de fundamentar, por meio da literatura, conceitos e relações de gestão de micro e pequenas empresas, características do gestor, assim como facilidades e dificuldades no desenvolvimento dos negócios.

\subsection{Gestão de micro e pequenas empresas}

$\mathrm{O}$ avanço da globalização e das tecnologias impactaram profundas mudanças no mercado de trabalho mundial, dentre estas a crescente competitividade das organizações e a reestruturação do trabalho. Tais mudanças refletem em iniciativas de negócios como estratégia para atender novas demandas de bens e serviços (CUNHA; SILVA; YAMAGUSCHI, 2011).

Neste contexto, os mesmos autores destacam que no Brasil, a abertura de empresas teve ampla visibilidade a partir da década de 90, por fatores como a implementação do plano real que permitiu a queda da inflação, com a renegociação da dívida externa, passando a atrair novos recursos e investimentos estrangeiros no país, com o processo de privatização e com a fusão e aquisição de empresas.

Nesse período o avanço comercial instaurou nas grandes empresas brasileiras a necessidade de buscar alternativas para aumentar a competitividade e se manter no mercado. Diante da demanda, as empresas investiram em tecnologia e reduziram os custos com mão de obra assalariada. Perante o desemprego, muitos profissionais começaram a criar novos negócios, na maioria dos casos, sem ter experiência no ramo (DORNELAS, 2012). Nessa conjuntura, as micro e pequenas empresas passaram a ocupar um patamar de relevância na economia do país.

Frente à expansão das micro e pequenas empresas surge também à necessidade de qualificar os gestores e seus processos de trabalho. Dessa forma, o Governo Federal, por meio do programa denominado Brasil Empreendedor, capacitou microempreendedores e criou entidades de apoio ao público 
empreendedor, dentre elas o Serviço Brasileiro de Apoio às micro e pequenas empresas (SEBRAE) e a Sociedade Brasileira para Exportação de Software (SOFTEX) (CUNHA; SILVA; YAMAGUSCHI, 2011).

Nesse contexto, a pesquisa apresentada pelo GEM (2018) evidenciou que a taxa de empreendedores em estágio inicial no Brasil em 2018 foi de 17,90\% e de empreendedores estabelecidos $20,20 \%$. Este último número representava 51,90 milhões de brasileiros com idade entre 18 e 64 anos com um negócio ou envolvidos na criação de um, demonstrando o crescimento da atividade no país e a necessidade de qualificar os novos gestores, observando características e competências descritas a seguir.

\subsection{Características dos gestores de micro e pequenas empresas}

Na visão de Filardi, Barros e Fischmann (2014), não existe um único e exclusivo padrão de perfil de gestores. Existem características que contribuem para a sua identificação, sendo essas: alto nível de domínio nas tomadas de decisões, prevalência nos princípios éticos, foco, determinação, respeito, poder de persuasão, empatia, resiliência, facilidade em agregar valor em equipes, forte caráter em desenvolver novos talentos, boa comunicação, criatividade, habilidade e percepção de mudanças futuras em relação ao mundo competitivo dos negócios, entre outras (FILARDI; BARROS; FISCHMANN, 2014).

Para Dornelas (2012), o gestor possui a capacidade de analisar oportunidades e ameaças, assumindo riscos calculados. O mesmo autor afirma ainda que o gestor é dotado de sensibilidade para as negociações, possui um bom tino financeiro e tem capacidade de planejamento e ação.

Segundo Cunha, Silva e Yamaguschi (2011), o gestor de sucesso é aquele que através de uma simples oportunidade transforma inúmeras possibilidades de lucratividade para a organização, seu perfil apresenta autoconfiança, tomada de decisões assertivas no momento adequado a cada situação. Dolabela contribui destacando que um gestor deve ter capacidade de destacar-se, pensando e agindo diferente dos demais. "[...] é alguém que sonha e busca transformar seu sonho em realidade" (DOLABELA, 2008, p. 23).

Com base nas ideias do canadense Louis Jacques Filion, Dolabela (2003) enfatiza que o gestor deve desenvolver suas competências com base no autoconhecimento, no conhecimento do setor, na rede de relações, na energia e na liderança. Um sujeito com potencial gerencial é um visionário, faz uso de sua criatividade e conhecimento para vislumbrar novas oportunidades. Um gestor identifica oportunidades, independente dos recursos disponíveis, pois consegue buscar, administrar e capacitar recursos.

Dornelas (2007) pontua algumas características que constituem um perfil gerencial, entre elas: são visionários; sabem tomar decisões; são indivíduos que fazem a diferença; sabem explorar ao máximo as oportunidades; são determinados e dinâmicos; são dedicados; são otimistas e apaixonados pelo 
que fazem; são independentes e constroem o próprio destino; são líderes e formadores de equipes; são bem relacionados; são organizados; sabem planejar; possuem conhecimento; assumem riscos calculados; e criam valor para a sociedade.

A partir do autor citado, observa-se que gestores de sucesso devem possuir capacidade de planejar, utilizar os recursos disponíveis de forma criativa, ter paixão pelo que fazem e aceitar assumir riscos, mesmo sabendo que podem fracassar.

Neste contexto, Escarlate (2010) destaca que o SEBRAE define dez características para o Comportamento Empreendedor (CCEs), que são: estabelecimento de metas; busca de oportunidades e iniciativas; busca de informações; persuasão e rede de contatos; exigência de qualidade e eficiência; planejamento e monitoramento sistemático; comprometimento; persistência; disposição para correr riscos calculados e independência e autoconfiança. Essas características facilitam a gestão de micros e pequenas empresas, tema que é abordado no item a seguir.

\subsection{Facilidades e dificuldades na gestão de micro e pequenas empresas}

Para Dornelas (2007), o gestor possui liberdade para estabelecer e colocar em prática sua própria metodologia e utilizar as estratégias que mais lhe convém perante seus objetivos e metas. Outro aspecto que facilita a gestão do seu próprio negócio é que o gestor possui flexibilidade para cumprir seus horários e a rotina de trabalho, bem como pode se autorrealizar trabalhando com o que almejou para si.

Dolabela (2003) salienta que a criação de um negócio permite ao empreendedor ser protagonista de seu destino, recriar e modificar-se constantemente, investindo num ambiente de trabalho que acredita e que deseja para si. Gerir seu próprio negócio permite liberdade nas decisões e ações de seu trabalho, possibilita aprendizados constantes de diferentes formas, além de independência e realização pessoal (DORNELAS, 2007).

Ainda, a gestão de uma micro ou pequena empresa possibilita criar um plano de negócios, construindo suas próprias referências do percurso (DOLABELA, 2002). Gerir um negócio oportuniza a organização de um projeto de vida, impulsionando o empreendedor na busca incessante de tentar realizálo (DOLABELA, 2008). Além disso, empreender proporciona um sonhar alto, vislumbrando um futuro de sucesso. Essas características contribuem para a construção de empreendimentos coerentes às demandas do mercado (CUNHA; SILVA; YAMAGUSCHI, 2011).

Dolabela (2002) define empreender como um impulso para criar ou aprimorar um negócio. Porém, esse processo envolve dificuldades, pois o empreendedor necessita fazer de tudo para que seu empreendimento se mantenha no mercado. Nesse percurso, o empreendedor enfrentará situações 
de pressão e em alguns momentos terá que lidar com a frustração de decisões que não deram certo. Para o mesmo autor, um empreendedor precisa conviver com o excesso de carga horária, o risco e as incertezas nos momentos da tomada de decisão, bem como com a competitividade e as oscilações do mercado.

As mudanças políticas e altas taxas de inflação que agregam custos nos produtos e serviços são fatores que interferem diretamente nos empreendimentos, dificultando, muitas vezes, o bom andamento do negócio (DOLABELA, 2002). Dornelas (2012) menciona que essa dificuldade é bem intensa no contexto dos gestores brasileiros, visto que o Brasil não possui um sistema adequado de apoio a novas empresas. Entretanto, esse não deve ser um motivo para os gestores acreditarem no insucesso de seus empreendimentos.

Outro fator que pode mostrar-se como uma dificuldade a ser superada pelo gestor é a aceitação da família perante sua nova atuação no mercado competitivo. Com o passar do tempo os imprevistos e obstáculos poderão ser maiores ou menores, e desta forma a reação de familiares e amigos mais próximos podem impactar as tomadas de decisões do gestor (DOLABELA, 2002).

Cunha, Silva e Yamaguschi (2011) destacam que nem todos os gestores possuem planejamento adequado e capacidades para a administração dos processos de trabalho. Dessa forma, não conseguem sucesso na micro ou pequena empresa. Nesses casos, Dornelas (2012) recomenda a importância dos gestores obterem informações que possam auxiliar a direção dos negócios, para refletir sobre suas ações e preparar-se para as dificuldades naturais que interferem nesse processo.

Discorrida a revisão de literatura, na seção seguinte é apresentado o método de pesquisa para o alcance dos objetivos propostos.

\section{MÉTODO DA PESQUISA}

Esta pesquisa caracteriza-se como qualitativa e de estudo de casos múltiplos. De acordo com Flick (2009), a pesquisa qualitativa se direciona a analisar casos concretos em suas particularidades locais e temporais. Marconi e Lakatos (2017) contribuem a esse respeito pontuando que a abordagem qualitativa tem como premissa analisar e interpretar aspectos mais profundos, fornecendo análises mais detalhadas acerca das investigações.

Para Minayo (2017), o método qualitativo se dirige a explorar a intensidade dos fenômenos estudados. O processo de investigação se direciona a observar: "[...] a dimensão sociocultural, expressa por meio de crenças, valores, opiniões, representações, formas de relação, simbologias, usos, costumes, comportamentos e práticas" (MINAYO, 2017, p. 2).

De acordo com Yin (2005, p. 32), o estudo de caso se caracteriza como “[...] uma investigação empírica que investiga um fenômeno contemporâneo dentro 
de seu contexto de vida real, especialmente quando os limites entre o fenômeno e o contexto não estão claramente definidos". Ele pode ser classificado como único ou múltiplo, sendo múltiplo quando envolve mais de um caso. O estudo de caso múltiplo proporciona, por meio das evidências dos casos, um estudo mais robusto acerca da temática estudada (VENTURA, 2007).

Este estudo caracteriza-se como qualitativo e estudo de casos múltiplos por desejar analisar, a partir de gestores de micro e pequenas empresas, quais características e competências consolidam seus negócios.

Os sujeitos desta pesquisa são cinco gestores de micro e pequenas empresas do Vale do Taquari/RS33 , escolhidos por conveniência e acessibilidade. $\mathrm{Na}$ concepção de Minayo (2017), sujeitos são indivíduos, que estão inseridos em vivências sociais e detêm atributos que o pesquisador pretende conhecer. A escolha por conveniência e acessibilidade se deu pela disponibilidade de gestores de micro e pequenas empresas do Vale do Taquari/RS que aceitaram participar da pesquisa. Além disso, optou-se por convidar para a pesquisa gestores de micro e pequenas empresas de diferentes segmentos do mercado.

Para a coleta dos dados deste estudo, utilizou-se a entrevista semiestruturada (APÊNDICE A), tendo como base para a elaboração do roteiro autores apresentados na seção 2.2. De acordo Lakatos e Marconi (2010), esse tipo de entrevista amplia a interação entre entrevistador e entrevistado, facilitando o surgimento de respostas espontâneas e permitindo uma cobertura mais profunda sobre determinados assuntos. Por esse motivo, o entrevistador deve ficar atento à discussão e fazer perguntas adicionais para esclarecer questões que não foram contextualizadas ou para recompor o contexto da entrevista, caso o entrevistado tenha dificuldades com o tema.

As cinco entrevistas deste estudo foram realizadas no período de 02 a 30 de setembro de 2019, em horário comercial, nas dependências de cada micro ou pequena empresa, nas cidades de Arroio do Meio, Capitão, Cruzeiro do Sul, Dois Lajeados e Doutor Ricardo, pertencentes ao Vale do Taquari/RS. As entrevistas foram gravadas e, posteriormente, transcritas.

3 O Vale do Taquari é uma região situada no centro do estado do Rio Grande do Sul, conforme a regionalização funcional e de planejamento instituída pelos Conselhos Regionais de Desenvolvimento (COREDEs). É importante explicar que os COREDEs atuam para a promoção de políticas e ações que visam ao desenvolvimento regional e sua divisão compreende 28 regiões. De acordo com esta regionalização, o Vale do Taquari é composto por 36 municípios que totalizam $4.826,4 \mathrm{Km}^{2}$. A população estimada em 2018 foi de 369.710 habitantes (FEE, 2018), a grande maioria de origem alemã, italiana e açoriana. A economia é diversificada, com agricultura familiar, agropecuária e agroindústria, além da indústria de transformação, com predominância na fabricação de produtos alimentícios (cortes de aves, suínos derivados de leite e de erva-mate, balas, pirulitos, refrigerantes, sucos, água, sorvetes, chocolates e produtos coloniais), de móveis, calçados, fármacos, metalmecânicos, gemas e joias, produtos de limpeza e higiene, e cosméticos (SEPLAN, 2015). 
O processo de análise das entrevistas tem aproximações com a técnica de conteúdo da Bardin, que analisa as comunicações. Ou seja, busca-se uma descrição objetiva e sistemática do conteúdo relatado nas comunicações (BARDIN 2011).

A mesma autora aponta que esse tipo de análise pode compreender três etapas, sendo elas: a pré-análise; a exploração do material e o tratamento dos resultados. A pré-análise se destina a sistematizar os resultados para conduzir as operações sucessivas da análise. A segunda etapa se dedica a explorar o material coletado visando classificar os conteúdos, agrupando-os e captando os sentidos de suas comunicações. E a terceira visa o tratamento dos resultados, destacando as informações fornecidas pela análise (BARDIN, 2011).

Assim, na pré-análise deste estudo, os conteúdos das entrevistas foram transcritos e organizados seguindo as questões do roteiro semiestruturado. $\mathrm{Na}$ sequência, buscou-se explorar os relatos com vista a identificar os conteúdos mais presentes nas entrevistas. Para a terceira etapa com base nos conteúdos emergentes construiu-se a análise, que será apresentada a partir das questões norteadoras do roteiro, demonstrando assim as características dos gestores de micro e pequenas empresas que consolidam seus negócios.

Mesmo com estes cuidados, todo método apresenta limitações. No processo de coleta de dados, dois gestores não aceitaram participar do estudo. Além disso, em relação ao porte das empresas, uma é de pequeno porte e quatro são microempresas.

\section{ANÁLISE DOS RESULTADOS}

Esta seção analisa os dados coletados. Inicia-se a apresentação com a caracterização das empresas participantes da pesquisa, conforme Quadro 2. Na sequência (Quadro 3), há a descrição do perfil dos gestores das empresas. Tanto as empresas quanto os gestores são, respectivamente, identificados por letras e números, visando preservar suas identidades e privacidades.

Quadro 2 - Caracterização das empresas participantes da pesquisa

\begin{tabular}{|c|c|c|c|c|c|}
\hline Empresa & Localização & Segmento & $\begin{array}{c}\text { Porte da } \\
\text { empresa }\end{array}$ & $\begin{array}{c}\text { Tempo de } \\
\text { atuação }\end{array}$ & $\begin{array}{c}\text { Número de } \\
\text { funcionários }\end{array}$ \\
\hline E1* & $\begin{array}{c}\text { Arroio do } \\
\text { Meio }\end{array}$ & Comércio & Micro & 10 & 03 \\
\hline E2 & Capitão & Indústria & Pequeno & 15 & 30 \\
\hline E3 & $\begin{array}{c}\text { Cruzeiro do } \\
\text { Sul }\end{array}$ & Comércio & Micro & 34 & 03 \\
\hline E4 & $\begin{array}{c}\text { Dois } \\
\text { Lajeados }\end{array}$ & Serviços & Micro & 28 & 08 \\
\hline
\end{tabular}




\begin{tabular}{|c|c|c|c|c|c|}
\hline Empresa & Localização & Segmento & $\begin{array}{c}\text { Porte da } \\
\text { empresa }\end{array}$ & $\begin{array}{c}\text { Tempo de } \\
\text { atuação }\end{array}$ & $\begin{array}{c}\text { Número de } \\
\text { funcionários }\end{array}$ \\
\hline E5 & $\begin{array}{c}\text { Doutor } \\
\text { Ricardo }\end{array}$ & Comércio & Micro & 06 & 07 \\
\hline
\end{tabular}

Fonte: Elaborado pelos autores, a partir das respostas dos entrevistados (2019).

*Legenda: E1 leia-se Empresa 1, e assim sucessivamente.

Conforme pode ser observado no Quadro 2, das cinco empresas pesquisadas, predominam as micros na área comercial, entre 6 e 34 anos de existência, e até 7 funcionários. A microempresa na área de serviços possui 28 anos de atuação e 8 funcionários; e a indústria de pequeno porte 15 anos de atuação e 30 funcionários.

Dependendo do tempo de atuação das empresas, é possível caracterizálas como estabelecidos ou não. Com base nos dados do GEM (2018), todos os gestores que possuem negócios com mais de 42 meses de funcionamento, são caracterizados empreendedores estabelecidos. A partir disso, é possível afirmar que todos os respondentes possuem empresas estabelecidas.

Em relação ao perfil dos gestores, 2 são do sexo feminino, possuem 32 e 27 anos, uma casada e com 2 filhos e outra solteira. Ambas possuem Ensino Superior Completo. Os demais participantes são do sexo masculino, possuem 56, 54 e 60 anos. Ambos casados e com filhos. Dois tem Ensino Fundamental Completo e o outro Ensino Médio Completo.

Por meio dessas informações, observa-se a predominância de gestores do sexo masculino, com idade média de 57 anos, casados e com filhos. Quanto à escolaridade, dois gestores possuem Ensino Fundamental Completo, dois Ensino Superior Completo e um Ensino Médio Completo.

Após identificar a caracterização das empresas e o perfil dos gestores participantes da pesquisa, questionou-se sobre o que os levou a constituir a empresa. O gestor G2/E2, relata que iniciou sua empresa a partir da vontade de crescer profissionalmente e da ajuda de um sócio. "A escolha pelo ramo industrial se deu por perceber a necessidade de uma serraria de desdobramento de madeiras no município e no seu entorno". Também afirma que muitos foram os desafios, pois não dominava o ramo na época, além da dificuldade de recrutar pessoas para compor o quadro funcional e de formar uma carteira de clientes.

Para o gestor G3/E3, o desejo de crescer e ser dono da própria empresa também foi o ponto de partida. "Há uns 20 anos já passados eu sentia uma grande vontade de não precisar trabalhar como funcionário de alguém. Eu queria ter um estabelecimento próprio". Então teve a oportunidade de, juntamente com um sócio, assumir e gestão de uma empresa familiar.

A gestora G1/E1, tomou coragem de constituir a empresa a partir do apoio do sócio. "Sempre tive sonhos e percebia a necessidade de uma empresa 
comercial no nosso município, então com o apoio do sócio tornei um desses sonhos realidade". A G5/E5, comenta que há muito tempo tinha vontade de se tornar gestora da própria empresa. "Isso fazia parte dos meus sonhos".

É possível observar, por meio do depoimento dos respondentes, que o desejo de ter o próprio negócio é um dos seus objetivos de vida. Esse resultado vem ao encontro da pesquisa realizada pelo GEM, em que revela que o $4^{\circ}$ maior sonho dos brasileiros é ter seu próprio negócio (GEM, 2018).

Em relação à escolha da área da atuação, a maioria dos gestores referiu ter identificado e analisado uma demanda de mercado ou uma área que estava em expansão. Frente a essa colocação, observa-se nos gestores o que Dornelas (2012) recomenda que é analisar as oportunidades e ameaças antes de empreender, assumindo riscos calculados. Para o mesmo autor, um empreendedor sabe explorar as oportunidades, pois apresenta visão sistêmica e capacidade de transformar ideias em ações.

No entanto, apesar de saber explorar as oportunidades e analisar cenários, antes de empreender os respondentes referiram não ter experiência no ramo quando iniciaram seus negócios. Tal depoimento vai ao encontro de Dornelas (2012) quando destaca que a maioria dos gestores de micro e pequenas empresas iniciam um empreendimento sem ter experiência no ramo de atividade.

Nessa conjuntura, podemos evidenciar que apesar do SEBRAE fornecer possibilidades de qualificação e consultoria para gestores de micro e pequenas empresas, neste estudo, os respondentes preferem desenvolver o empreendimento conforme sua visão de mercado.

Diferente do que é apontado por Dornelas (2012), tais gestores não iniciaram suas atividades devido ao desemprego, mas planejaram o negócio pelo desejo de não ser empregado, pela vontade de crescer, por uma oportunidade de negócio ou na busca de concretização de um sonho.

Também é possível observar que dos cinco entrevistados, quatro inicialmente compartilharam a gestão com um sócio. Na visão de Miglioli (2006), a administração de uma empresa está diretamente relacionada à tomada de decisão, que garante uma boa continuidade do negócio através das habilidades dos gestores nos processos decisórios diários. E, segundo o autor, muitas vezes o processo decisório é compartilhado com um familiar ou sócio.

O questionamento seguinte foi sobre o quanto adotam instrumentos para gestão dos processos de trabalho e gestão de pessoas. O gestor G2/E2 destacou que adota um método específico de gestão de processos que atende suas demandas diariamente. "Nossa empresa não possui modelo específico de gestão de pessoas, esta parte é realizada de maneira mais informal, diretamente eu e o candidato. Já a gestão de processos é realizada através de programas específicos que atendem nossa rotina". 
A gestora G5/E5 sempre adotou um modelo específico de gestão de processos, mas não de pessoas. "De processos sim, utilizamos pelo fato de ser mais fácil de trabalhar diariamente, mas de pessoas não temos nada formal". Os gestores G1/E1, G3/E3 e G4/E4 não possuem um modelo de gestão de pessoas e/ou de processos instituído.

Os depoimentos da maioria dos respondentes destacam que não utilizam modelos de gestão em seus empreendimentos. Contudo, Cunha; Silva; Yamaguschi (2011) alertam para a evolução tecnológica e as variáveis econômicas, sociais, culturais e ambientais interferem nos negócios, requerendo determinadas iniciativas e práticas sem as quais as empresas não sobreviverão a longo prazo.

Outro questionamento feito aos entrevistados foi sobre quais os desafios enfrentados para empreender e como os superou. A gestora G5/E5 diz que o maior obstáculo enfrentado para começar a empresa foi a falta de conhecimento do segmento de atuação, na qual o sócio minimizou as dificuldades. Para ela, "Na teoria parece tudo muito fácil, mas na prática não é bem assim. É preciso muito trabalho em equipe, humildade, compromisso e comunicação para gerir uma empresa".

A gestora G1/E1 menciona que teve dificuldade em fomentar uma carteira de clientes e fornecedores. Outro grande desafio que enfrentou foi começar a trabalhar sem possuir capital de giro. No entanto, "Para superar desafios no curto e até longo prazo, é preciso acompanhar tendências de mercado, pois a inovação é fundamental para atingir as metas".

Para o gestor G4/E4, o principal desafio, na fase inicial da empresa, foi o elevado investimento realizado. "Não possuía muitos recursos, foi muito complicado superar isso". Para o mesmo respondente, fazer gestão de uma empresa de forma eficiente e eficaz, obrigatoriamente necessita "[...] ter muita paciência, flexibilidade e coragem para superar desafios diários".

Em síntese, observa-se pelos depoimentos dos respondentes que os maiores desafios estão relacionados a conhecimentos e limitações de capital, e buscam superá-los com muito trabalho, humildade, compromisso, esforço, coragem e criatividade. Acredita-se que a falta de preparo dos profissionais responsáveis pela gestão das micro e pequenas empresas conduzem a tomadas de decisões empíricas, baseadas em preocupações imediatas, requerendo muito esforço para se manterem competitivas (DORNELAS, 2012). O mesmo autor complementa afirmando que essas empresas devem atentar para a adoção de práticas de gestão simples e ágeis, direcionando estrategicamente suas ações para otimizar recursos e esforços.

Seguindo o processo de exploração das características e competências que consolidam os negócios, os gestores também foram questionados acerca de quais competências consideram necessárias para gerir uma empresa e quais as expectativas para seu empreendimento. Para o gestor G2/E2, as competências 
necessárias são "[...] muita força de vontade e capacidade de reinvestir parte do capital de giro". Suas expectativas integram "[...] maior desenvolvimento da empresa, através da aquisição de novas máquinas modernas e assim poder aumentar a carteira de clientes no exterior, pois é lá que existe a real possibilidade de atingir maiores resultados".

$\mathrm{O}$ gestor G3/E3 destaca que “[...] para gerir uma empresa independentemente do tamanho que for é imprescindível possuir muita força de vontade e sempre acreditar que dias melhores chegarão, com muita persistência e coragem". Suas expectativas referem-se a "[...] manter o foco para atingir os objetivos". A gestora G5/E5 destacou que para gerir uma empresa é preciso "[...] paciência e jogo de cintura, além de, aos poucos ir modernizando a empresa".

A força de vontade citada pelos respondentes pode estar relacionada ao excesso de atividades e a centralização de poder, até certo ponto natural, se considerado o tamanho da empresa e número de funcionários, contudo comprometedora para a viabilidade e sustentabilidade do modelo de negócio, afirmam Souza e Qualharini (2007). Para os mesmos autores, um dos primeiros passos para o sucesso de uma micro ou pequena empresa é combater o caráter de informalidade para tornar a empresa apta a adotar técnicas e métodos de administração adequadas a sua realidade e expertise (SOUZA; QUALHARINI, 2007).

Os entrevistados também foram questionados sobre quais características julgam ser necessárias a um gestor de micro e pequenas empresas. As respostas podem ser visualizadas na Figura 1, que é uma nuvem de palavras, na qual quanto maior a palavra, mais repetições ela teve nas respostas dos gestores e proprietários das empresas participantes. 
Figura 1 - Características de um gestor de micro e pequenas empresas

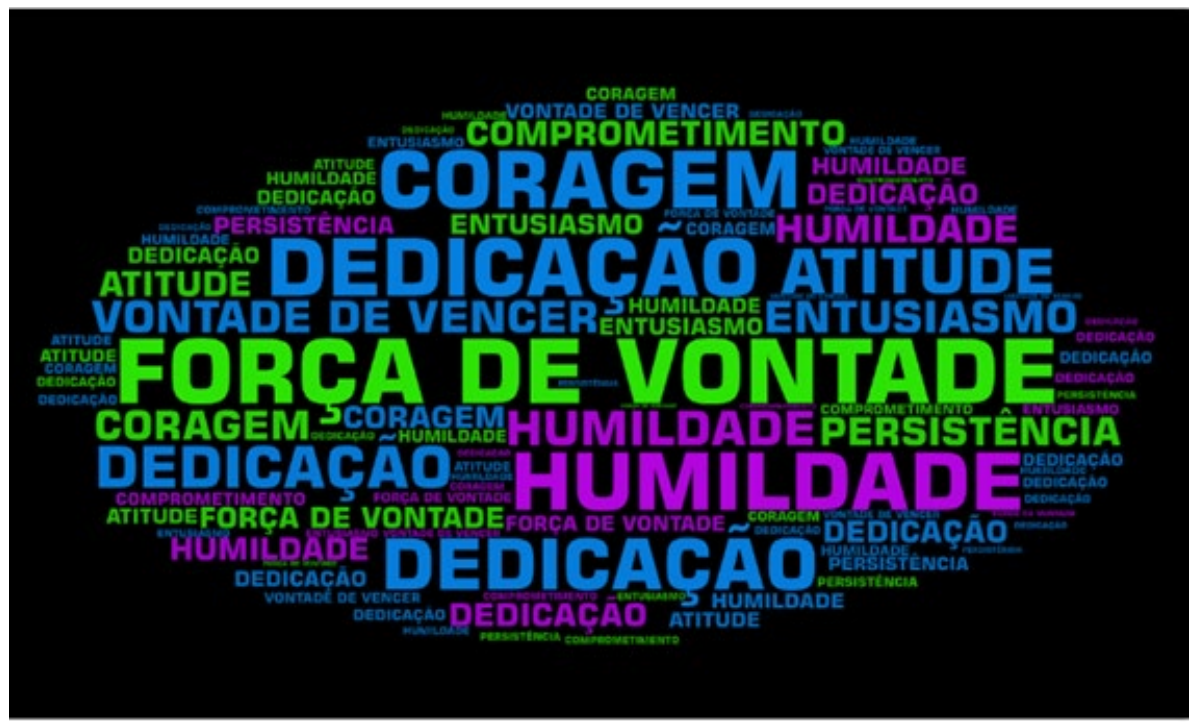

Fonte: Elaborada pelos autores, a partir das respostas dos entrevistados (2019).

Como pode ser visualizado na Figura 1, as características mais citadas entre os entrevistados foram: força de vontade, dedicação, humildade, coragem, persistência, vontade de vencer, entusiasmo, comprometimento e atitude. Das quinze características que contribuem para um perfil gerencial, na concepção de Dornelas (2007), seis são identificadas entre os entrevistados.

A coragem, vontade de vencer e força de vontade se assemelham a característica visionária, apontada por Dornelas (2007). Para o autor, gestores com essa característica apresentam a habilidade de concretizar seus sonhos. A atitude se enquadra na tomada de decisão, descrita como um fator chave para o sucesso, já que impulsiona o gestor para além da tomada de decisão. A dedicação e o comprometimento correspondem a menção de dedicação conferida por Dornelas (2007) como uma capacidade de dedicação contínua e intensa.

Por sua vez, a persistência pode ser incluída à característica nomeada pelo autor como determinação e dinamismo. Segundo ele, sujeitos com essas competências implementam ações com total comprometimento, superando as adversidades e obstáculos. Também são dinâmicos e inconformados com rotinas. A coragem possui forte relação com a habilidade de fazer a diferença, pois permite a transformação de algo difícil em uma realidade possível. $\mathrm{O}$ entusiasmo e a humildade correspondem à capacidade de ser líder e formador de equipe, visto que através da empatia, os gestores valorizam, estimulam e recompensam suas equipes, sendo respeitados e adorados por elas (DORNELAS, 2007). 
A Figura 2 apresenta as características pessoais que influenciam a gestão de cada uma das empresas dos entrevistados. Como no quadro anterior, as respostas podem ser visualizadas na nuvem de palavras, na qual quanto maior a palavra, mais repetições ela teve nas respostas dos entrevistados.

Figura 2 - Características pessoais que influenciam a sua gestão

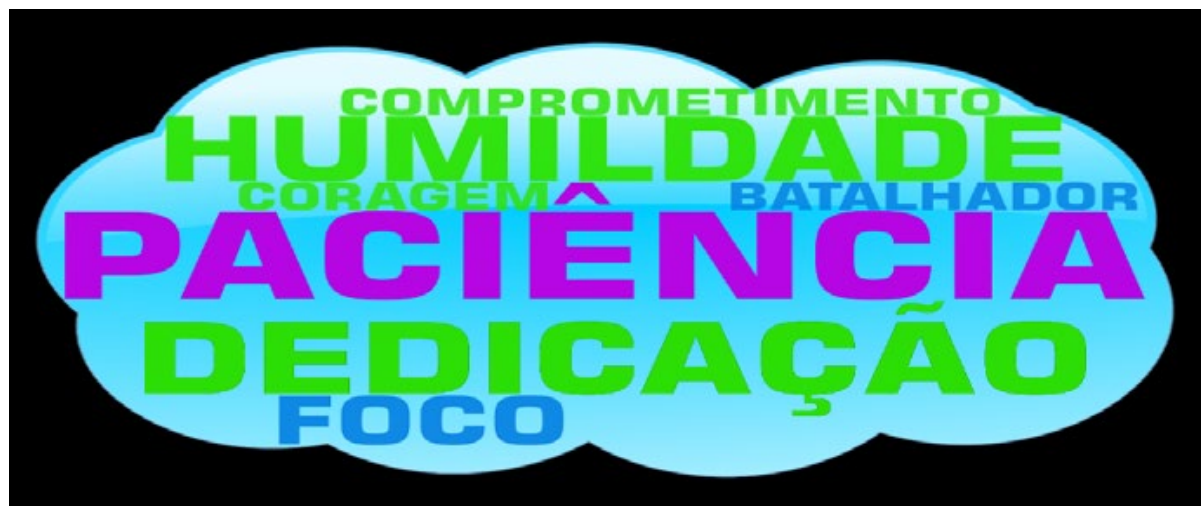

Fonte: Elaborada pelos autores, a partir das respostas dos entrevistados (2019).

A partir da Figura 2 é possível identificar as principais características dos entrevistados, destacando-se: paciência, humildade, dedicação, foco, batalhador, coragem e comprometimento. Tais características se assemelham a sete das dez definidas pelo Sebrae no estudo denominado "Características de Comportamento Empreendedor" (CCEs), citadas por Escarlate (2010).

A dedicação está diretamente relacionada com eficiência, característica esta mencionada entre as CCEs, pois onde não há dedicação, a busca por um trabalho eficiente torna-se mais difícil. As características como coragem, batalhador e comprometimento vão ao encontro da disposição para correr riscos calculados, independência e autoconfiança, mencionadas nas CCEs. As características como paciência, humildade e foco estão correlacionadas com explicações que as CCEs apresentam, de que a busca por informações, novas oportunidades e comprometimento são pré-requisitos para uma organização manter-se em plena vida útil por várias décadas (ESCARLATE, 2010).

Se comparada às respostas das 'características que os respondentes julgam ser necessárias a um gestor de micro e pequenas empresas' com as respostas das 'características pessoais que influenciam a sua gestão', observa-se coerência e até repetição de características, tais como: dedicação, humildade, coragem e comprometimento.

Outro questionamento foi como se percebem como empreendedores. O gestor G2/E2 referiu ser estratégico: "Sou determinado, pois no atual momento da economia, muitas vezes tenho que fazer reajustes e cortes para manter a empresa de pé". A gestora G1/E1 destaca que "Sou realizada, feliz e estou 
conseguindo atingir meus objetivos". O gestor G3/E3 se percebe como "[...] determinado, tenho sede de inovação, de aprender".

As afirmações dos respondentes, de modo geral, demonstram que os desafios diários lhes impulsionam para a realização, já que se sentem motivados a cada superação. Para Dolabela (2002), as verdadeiras oportunidades dificilmente estão expostas de forma clara, ao contrário, são geralmente de difícil acesso, mas existem para aquelas pessoas que as detectam mesmo sem enxergá-las.

Para finalizar, os entrevistados foram questionados sobre como acreditam que suas características contribuem para a gestão do negócio. Conforme o gestor G5/E5, trata-se de uma pergunta fácil de responder: "Para o negócio dar certo não existe meio termo, ou se faz com toda a vontade e bem feito ou não se faz". O gestor G2/E2 acredita que "[...] por eu ter muita paciência já é uma grande contribuição, pois para manter um cliente e atendê-lo bem, requer esta competência".

Observa-se coerência nas respostas na medida em que o "cliente" é citado como um dos elementos centrais da existência da empresa. Neste aspecto, Alves (2004) destaca que mesmo diante de reconhecidas dificuldades que enfrentam as micro e pequenas empresas, o cliente é prioridade em qualquer modelo de gestão.

\section{CONSIDERAÇÕES FINAIS}

As construções deste estudo possibilitaram refletir sobre quais características consolidam as micro e pequenas empresas. Dos cinco entrevistados, somente dois referiram utilizar em suas práticas gestão de pessoas ou de processos, o que demonstra um desafio a ser superado, considerando a complexidade e competitividade do mercado.

As dificuldades apontadas pelos respondentes são a falta de conhecimento no ramo de atuação, a busca por clientes e fornecedores, os investimentos elevados e a falta de recursos financeiros. Apesar dos desafios, foi possível identificar nos respondentes características como paciência, humildade, dedicação, foco, coragem e comprometimento para gerir e consolidar os negócios.

Este estudo demonstra ainda que as características mencionadas por Escarlate (2010) e Dornelas (2007) estão presentes nos gestores participantes da pesquisa, e são importantes para o desenvolvimento das micro e pequenas empresas. Porém, elas não são substitutivas à gestão de pessoas e de processos, quesitos estes que apareceram como deficitários no estudo, pois dos cinco respondentes somente dois referiram utilizar gestão de processos.

Vale destacar ainda que este trabalho considerou uma amostra por acessibilidade e conveniência, e não uma amostra probabilística. Por isso, propõe-se que este estudo seja replicado com amostras maiores que 
permitam considerar diferenças em relação a outras variáveis, aprofundando a compreensão da gestão de micro e pequenas empresas.

\section{REFERÊNCIAS}

ALVES, Joemar B. Gestão de clientes: a arte da conquista e manutenção do cliente. Rio de Janeiro: Qualitymark, 2004.

BARDIN, Laurence. Análise de conteúdo. 2. ed. São Paulo: Edições 70, 2011.

BONACIM, Carlos Alberto G.; CUNHA, Julio Araújo C. da; CORRÊA, Hamilton Luiz. Mortalidade dos empreendimentos de micro e pequenas empresas: causas e aprendizagem. Gestão \& Regionalidade, v. 25, n. 74, p. 61-78, mai./agos. 2009. Disponível em: <https:/ / www.redalyc.org/pdf/1334/133412626006.pdf>. Acesso em: 20 abr. 2019.

BRASIL. Lei complementar $n^{\circ} 123$, de 14 de dezembro de 2006. Institui o Estatuto Nacional da Microempresa e da Empresa de Pequeno Porte. Disponível em: <http:/ / www.planalto.gov.br/ccivil_03/Leis/LCP/Lcp147.htm\#art1>. Acesso em: 22 abr. 2019.

CUNHA, Caroline V. M. da; SILVA, Mayara V. da; YAMAGUSCHI, Nathalia M. Empreendedorismo: Histórias que motivam, despertam e encantam. Anuário da Produção Acadêmica Docente, v. 5, n. 12, p. 165-182, 2011. Disponível em: <https:/ / repositorio.pgsskroton.com.br/bitstream/123456789/1465/1/Artigo\%2011.pdf>. Acesso em: 04 mai. 2019.

DOLABELA, Fernando. Empreendedorismo a viagem do sonho: como se preparar para ser um empreendedor. Brasília: Agência de Educação para o Desenvolvimento, 2002.

DOLABELA, Fernando. Empreendedorismo uma forma de ser: saiba o que são empreendedores individuais e coletivos. Brasília: Agência de Educação para o Desenvolvimento, 2003.

DOLABELA, Fernando. Oficina do empreendedor. Rio de Janeiro: Sextante, 2008.

DORNELAS, José C. A. Transformando idéias em negócios. 4. ed. Rio de Janeiro: Elsevier, 2012.

DORNELAS, José C. A. Empreendedorismo na prática: mitos e verdades do empreendedor de sucesso. Rio de Janeiro: Elsevier, 2007.

ESCARLATE, Luiz F. Aprender a empreender. Brasília: Fundação Roberto Marinho, SEBRAE, 2010.

FILARDI, Fernando; BARROS, Filippe D.; FISCHMANN, Adalberto A. Do Homo empreendedor ao empreendedor contemporâneo: evolução das características 
empreendedoras de 1848 a 2014, v. 13, n.3, p. 124-140, jul./ set. 2014. Disponível em: <https:/ / www.redalyc.org/html/3312/331232580010/>. Acesso em: 04 mai. 2019.

FLICK, Uwe. Introdução à pesquisa qualitativa. Tradução Joice E. C. 3. ed. Porto Alegre: Artmed, 2009.

Global Entrepreneurship Monitor - GEM. Serviço Brasileiro de Apoio às Micro e Pequenas Empresas. SEBRAE. Empreendedorismo no Brasil - relatório executivo, 2018. Disponível em: < https:/ / datasebrae.com.br/wp-content/uploads/2019/02/ Relat\%C3\%B3rio-Executivo-Brasil-2018-v3-web.pdf>. Acesso em: 18 out. 2019.

GOLDENBERG, Mirian. A arte de pesquisar: como fazer pesquisa qualitativa em Ciências Sociais. 13. ed. Rio de Janeiro: Record, 2013.

LAKATOS, Eva Maria; MARCONI, Marina de A. Fundamentos de metodologia científica. 7. ed. São Paulo: Atlas, 2010.

MARCONI, Marina de A.; LAKATOS, Eva Maria. Metodologia científica. 7. ed. São Paulo: Atlas, 2017.

MARCONI, Marina de A.; LAKATOS, Eva Maria. Técnicas de pesquisa: planejamento e execução de pesquisas, amostragens e técnicas de pesquisas, elaboração, análise e interpretação de dados. 8. ed. São Paulo: Atlas, 2017.

MIGLIOLI, Afrânio M. Tomada de decisão na pequena empresa: studo multi caso sobre a utilização de ferramentas informatizadas de apoio a decisão. 2006. 107 f. Dissertação (Mestrado em Engenharia de Produção) - Escola de Engenharia de São Carlos, Universidade de São Paulo, São Carlos, 2006.

MINAYO, Maria C. de S. Amostragem e saturação em pesquisa qualitativa: consensos e controvérsias. Revista Pesquisa Qualitativa, São Paulo, v. 5, n. 7, p. 01-12, abril. 2017.

Serviço Brasileiro de Apoio às Micro e Pequenas Empresas. SEBRAE. O que é o Sebrae. Brasil, 2019. Disponível em: http:/ / www.sebrae.com.br/sites/PortalSebrae/ canais_adicionais/o_que_fazemos. Acesso em: 04 mai. 2019.

SCHMIDT, Serje; BOHNENBERGER, Maria C. Perfil empreendedor e desempenho organizacional. Revista de Administração Contemporânea, v. 13, n.3, p. 450-467, 2009. Disponível em: <http:/ / www.scielo.br/pdf/rac/v13n3/v13n3a07.pdf>. Acesso em: 04 mai. 2019.

\section{SECRETARIA DO PLANEJAMENTO, MOBILIDADE E DESENVOLVIMENTO} REGIONAL (SEPLAN). Perfil Socioeconômico Corede Vale do Taquari. Governo do Estado do Rio Grande do Sul. Secretaria do Planejamento, Mobilidade e Desenvolvimento Regional. Departamento Governamental. Porto Alegre, 2015. Disponível em: https:/ / planejamento.rs.gov.br/upload/arquivos/201603/17095341perfis-regionais-2015-vale-do-taquari.pdf. Acesso em: 05 mai. 2019. 
SOUZA, Wendel; QUALHARINI, Eduardo. O planejamento estratégico nas micro e pequenas empresas. III Workshop Gestão Integrada: Riscos e Desafios. Centro Universitário Senac. São Paulo, 2007. Disponível em: http:/ / www.sp.senac.br/ pdf/24848.pdf. Acesso em: 27 out. 2019.

VENTURA, Magda M. O estudo de caso como modalidade de pesquisa. Revista da Sociedade de Cardiologia do Estado do Rio de Janeiro, Rio de Janeiro, v. 20, n. 5, p. 383-386, set./out. 2007. Disponível em: <http:/ / sociedades.cardiol.br/socerj/ revista/2007_05/a2007_v20_n05_art10.pdf>. Acesso em: 01 dez. 2019.

VERGARA, Sylvia C. Projetos e relatórios de pesquisa em administração. 16. ed. São Paulo: Atlas, 2016. E-book. Disponível em: <https:/ /integrada.minhabiblioteca.com. br/\#/books/9788597007480/cfi/6/4!/4/2@0:0>. Acesso em: 25 mai. 2019.

YIN, Robert K. Estudo de caso: planejamento e métodos. Porto Alegre, RS: Bookman, 2005. 


\section{APÊNDICE A - Roteiro semiestruturado da entrevista direcionada a gestores de micro e pequenas empresas}

Perfil do empreendedor

1. Sexo:

2. Idade:

3. Estado civil:

4. Número de filhos:

5. Escolaridade:

\section{Sobre a empresa}

1. Segmento:

2. Tempo de atuação no mercado:

3. Quantidade de funcionários:

4. O que o levou a empreender:

5. Você é o empreendedor ou há sócio no negócio:

6. Como foi a escolha da área de atuação:

7. A empresa adota um modelo de gestão (de processos e de pessoas):

8. Quais os desafios que você enfrentou quando iniciou o empreendimento.

9. Quais as competências (conhecimentos, habilidades e atitudes) necessárias para gerir uma empresa:

10.Quais as expectativas para o desenvolvimento do empreendimento (curto, médio e longo prazos):

\section{Características pessoais}

1. Que características um empreendedor precisa ter:

2. Quais são as suas principais características e competências:

3. Como você acredita que suas características contribuíram e contribuem para a gestão do negócio:

4. Como você se descreve como empreendedor:

5. Você teve ou tem auxílio de pessoas para gerir o negócio:

6. Que recomendações daria a um gestor que está iniciando um negócio: 